\title{
Scientific and methodological principles of forming an assessment of the level of environmental safety of construction projects in urban areas
}

\author{
Vadim Bespalov ${ }^{1}$, Ekaterina Kotlyarova, ${ }^{1, *}$, and Rafael Adamyan ${ }^{2}$ \\ ${ }^{1}$ Don State Technical University, Socialisticheskaya Str., 162, 344022, Rostov-on-Don, Russia \\ ${ }^{2}$ Department of construction of staff of Yerevan municipality, Argishtii Str., 1, 0015, Yerevan, \\ Armenia
}

\begin{abstract}
At present, improving the environmental safety of capital construction objects for various purposes in urban areas is still an urgent goal and a rather complicated process to implement. To achieve it, you need, first of all, a scientifically based methodology for assessing the actual level of environmental safety of a particular construction object or urban economy and a list of necessary measures to increase it. Our earlier analysis of known methodological approaches to assessing the state of the urban environment allowed us to conclude that when assessing the level of environmental safety of capital construction objects for various purposes, it is necessary to take into account social, environmental, economic factors and take into account a number of limitations. In this regard, we conducted scientific research, on the basis of which the scientific and methodological principles of forming an assessment of the level of environmental safety of capital construction facilities for various purposes in urban areas were determined. At the same time, the basis for a consistent assessment of the level of environmental safety of construction objects for various purposes in urban areas, in our opinion, is a comprehensive consideration of environmental, economic and social criteria, each of which includes corresponding groups of parameters (environmental, social and economic) that determine the degree of environmental safety and sustainable development. Our approach allows, using the various characteristics of an urbanized area with different dimensions, to obtain the resulting criteria in a dimensionless form and thereby improve the methodology for calculating a comprehensive assessment of the environmental safety level of construction objects and urban facilities in urban areas.
\end{abstract}

\footnotetext{
* Corresponding author: ekkot.arch@gmail.com
} 


\section{Introduction}

An analysis of the well-known methodological approaches to assessing the state of the urban environment, which we performed at the previous stage of research, allows us to conclude that when assessing the level of environmental safety of capital construction objects for various purposes, it is necessary to take into account social, environmental, economic conditions and take into account a number of restrictions. Such a sequence of actions in modern research has not yet received a sufficiently complete development [1-3]. This can be explained by the fact that the theory of sustainable development of urbanized territories, being very large-scale, is still at the stage of improvement.

In this regard, we considered it necessary to conduct appropriate scientific research, on the basis of which we developed scientific and methodological principles for the formation of an assessment of the level of environmental safety of capital construction facilities for various purposes in urban areas.

\section{Materials and Methods}

In our opinion, well-known approaches to calculating the economic assessment of the state of the urban environment are most fully represented in [1, 4-5]. Consider the advantages and disadvantages of some of the above approaches.

So, in [1], the author proposes to use a relative (dimensionless) indicator of economic damage to the population and the urban environment $D_{\text {ri }}$, which is divided into two components:

- economic damage directly caused to the health of the population $\mathrm{D}_{\mathrm{dr}}$ (direct damage);

- economic damage caused to the population and the surrounding urban environment due to its degradation of $D_{\text {indr }}$ (indirect damage), and which is determined by the formula:

$$
D_{r i}=\left(D_{d r}+1\right)^{P_{d d r}} \cdot\left(D_{i n d r}+1\right)^{P_{\text {dindr }}}-1
$$

where: $P_{j}$ - weighting coefficients of direct and indirect damages, determined for the considered territory of urban development on the basis of statistical data.

Moreover, direct economic damage to the urban environment includes the following elements:

- economic damage associated with activities in the conditions of a polluted atmosphere $\mathrm{D}_{\mathrm{dr}}{ }^{\mathrm{atm}}$;

- economic damage associated with the use of polluted water $\mathrm{D}_{\mathrm{dr}}{ }^{\text {wat; }}$;

- economic damage associated with the use (for example, in the cultivation of vegetables and fruits) of polluted soil $\mathrm{D}_{\mathrm{dr}}$ soil;

- economic damage caused by direct exposure of physical fields on people $\mathrm{D}_{\mathrm{dr}}{ }^{\text {phys }}$.

Then the formula (1) will be the following:

$$
D_{d r}=\left(D_{d r}^{a t m}+1\right)^{P_{d d r}^{a t r}} \cdot\left(D_{d r}^{\text {wat }}+1\right)^{P_{d d r}^{\text {wat }}} \cdot\left(D_{d r}^{\text {soil }}+1\right)^{P_{d d r}^{\text {soil }}} \cdot\left(D_{d r}^{\text {phys }}+1\right)^{P_{d d r s}^{\text {phys }}}-1
$$

Indirect economic damage, according to the author of [1], similarly to direct economic damage also includes four elements:

- economic damage associated directly with air pollution $\mathrm{D}_{\text {indr }}{ }^{\text {atm; }}$;

- economic damage associated directly with the pollution of water resources of the considered urban area $\mathrm{D}_{\text {indr }}{ }^{\text {wat; }}$;

- economic damage associated directly with the pollution of the soil cover of the considered urban area $\mathrm{D}_{\text {indr }}$ soil, 
- economic damage caused by the impact of physical fields directly on the components of the urban environment $D_{\text {indr }}^{\text {phys }}$.

Thus, we can conclude that the scientific and methodological approach described in [1] is quite acceptable for use as a methodological base in our further studies, since it is economic damage to the urban environment that is the link between the factor of negative impact on the urban environment and indicators of technological and economic efficiency of urban construction and household facilities operation.

However, it must be taken into account that the main drawback of the considered methodology [1] is the absence of a number of specific proposals, in particular:

- to calculate the economic damage associated with the consumption of polluted atmosphere, water, food and external physical effects;

- to calculate the economic damage associated with environmental degradation from pollution of the atmosphere, water, territories and caused by external hazardous effects;

- the calculation of the weighting coefficients of each element of economic damage.

Another methodological approach that deserves special attention is described in [2], in which the author proposes to supplement the statistical assessment of technogenic risk with an economic assessment of the extent of damage to the urban environment. In our opinion, the combined use of statistical estimates using the theory of solutions and the economic foundations of the analysis of the problem under research will allow us to compare the economic effect of the operation of any urban construction facility and economy with the value of industrial pollution of the urban environment.

The approach proposed in [2] is based on the use of expert assessment of $\mathrm{K}$, that is, the probability of an accident at any object in the construction industry or urban economy to identify the environmental feasibility of construction and further operation of this object. Such expediency will be justified only in cases when the inequality is satisfied:

$$
K \leq \frac{L \cdot\left(P_{f}+I-X\right)}{\left(Z+Z_{p}\right) \cdot(1-L)+P_{f} \cdot L+(I-X) \cdot(2 L-1)}
$$

where: $L$ is the probability that additional studies of the suitability of the selected site for the construction of an urban facility in the light of modern requirements will give a positive result; $\mathrm{P}_{\mathrm{f}}$ - profit from the operation of the designed urban facility throughout the entire life cycle; I - the costs that the economy of the considered urban area will bear from the absence of this facility; $\mathrm{X}$ - the amount of investment in the construction of the facility; $\mathrm{Z}$ - the cost of restoration of the territory and the damage caused to the surrounding urban environment and the economy of the considered territory of the city in the event of an unforeseen accident; $Z_{p}$ - loss of profits from non-profit due to the long-term conservation of the urban construction object and the economy due to an accident.

However, it is proposed to choose the value of the probability of an unforeseen accident based on the experience of experts, which, in our opinion, gives very approximate and subjective results.

Considering the drawbacks of the methodology proposed in [2], in our further studies we consider it expedient to supplement the assessment of technogenic pollution of the urban environment with the amount of economic damage to this environment, as well as the economic effect of the operation of the considered urban construction facility and economy, which will allow us to analyze the feasibility of construction and operation of this facility at a given level of the negative impact it creates on the surrounding urban environment.

In accordance with the methodological approach taken as the basis in [5-7], the calculation formula for economic damage to air and water resources is the following:

$$
D_{\text {air (wat) }}=\sum_{j}\left(D_{\text {decondair }(\text { wat })_{j}} \times \sum_{k=1}^{n} M_{\text {air(wat) } k}\right) \times K_{\text {econair }(\text { wat })}
$$


where: $\mathrm{D}_{\text {air(wat) }}$ - economic damage to air (water resources) on the territory of the city under consideration at the k-that urban facility during the reporting period, thousand rubles; $\mathrm{D}_{\text {decondair (wat) }}$ - the indicator of specific damage (pollution price) to the atmosphere (water resources) caused by a unit of the reduced mass of pollutants at the end of the reporting period for the $\mathrm{j}$-th facility in the region under consideration, rubles/cond. cost.

$\mathrm{M}_{\mathrm{air}(\mathrm{wat}) \mathrm{k}}$ - reduced mass of pollutants received (approved for release or discharge) from k-th object, rub.cond.cost; $K_{\text {eair(wat) }}$ - the coefficient of the ecological situation and the environmental significance of the state of the atmosphere (water bodies), respectively.

In accordance with the works [5-7] we consider it necessary to calculate the reduced mass of pollutants according to the following formula:

$$
M_{\text {air (wat)k }}=\sum_{i=1}^{N} m_{i} K_{\ni i}
$$

where: $m_{i}$ - the actual mass of the i-th pollutant or group of substances with the same coefficient of relative environmental and economic hazard during the reporting time period, tons; $K_{3 i}$ - the coefficient of relative environmental and economic hazard for the $\mathrm{i}$ - th pollutant or group of substances; i - type of pollutant or group of substances; $\mathrm{N}$ - the amount of pollutants taken into account.

As a basis for calculating the reduced mass of pollutants, the approved values of maximum permissible concentrations (TLV) of pollutants in air or water of fishery reservoirs (as the most stringent) were used. The TLV values are used to determine the coefficients of viscous and economic hazard of pollutants in water bodies:

$$
K_{E i}=\frac{1}{T L V_{i}}
$$

The value of the economic damage from soil pollution by chemicals can be determined by the following formula:

$$
D_{\text {soil }}=D_{\text {decdsoil }} \cdot \sum_{j} S \cdot K_{j} \cdot K_{n j}
$$

where: $D_{\text {soil }}$ - economic damage from soil cover pollution with the $j$-th chemical substance during the reporting period, thousand rubles; $\mathrm{D}_{\text {decdsoil }}$ - specific economic damage to soils in the considered area of the city territory, thousand rubles / ha; $\mathrm{S}$ - the square of soil cover, ha; $K_{j}$ - coefficient taking into account the hazard class of the $j$-th chemical; $K_{n j}-$ coefficient of natural and economic significance of the soil cover in the considered area of the urban territory.

The formula for determining the economic damage to the urban environment for all types of pollution by physical fields, in accordance with the method described in [8], has the form:

$$
y_{j}=\gamma \sum_{L_{n}^{\min }}^{L_{u}^{\max }} A\left(L_{H}\right) \cdot N_{H}\left(L_{n}\right)+\gamma \sum_{L_{\not \mu}^{\min }}^{L_{\not}^{\max }} B\left(L_{д}\right) \cdot N_{д}\left(L_{\not}\right)
$$

where: $\gamma$ - factor equal to 1,0, rub./(men · year); $\mathrm{A}(\mathrm{LH}), \mathrm{B}(\mathrm{L} Д)$ - dimensionless quantities depending on the level of exposure of physical fields at night and daytime, respectively; $\mathrm{N}_{\mathrm{H}}$ $\left(\mathrm{L}_{\mathrm{H}}\right)$-the number of people living (working) in the territory being considered, where the total (from all sources) is equal to exposure of physical fields when average annual night time is important, equal $\mathrm{L}_{\mathrm{H}}$, man; $\mathrm{NД(LД)} \mathrm{-} \mathrm{the} \mathrm{same,} \mathrm{with} \mathrm{average} \mathrm{annual} \mathrm{night} \mathrm{time,} \mathrm{man;}$ $\mathrm{L}^{\mathrm{max}}$ - dimensionless quantity numerically equal to the maximum value of $\mathrm{L}$ in residential accommodations in the calculated territory, respectively, at night and daytime, rounded to the nearest whole number; $L^{\min }$ - a dimensionless quantity numerically equal to the minimum value of $\mathrm{L}$ in residential accommodations in the territory under consideration, 
respectively, at night and daytime, rounded to the nearest whole number. According to formulas $(4,7,8)$, the amount of economic damage to the urban environment, on the one hand, is associated either with the concentration of pollutants or with the level of exposure of physical fields, that is, with the intensity of the negative impact, and, on the other hand, represents basis for determining fees for negative environmental impacts.

To assess the environmental risks of urban infrastructure and urban facilities, it is advisable to use the concept of individual environmental risk proposed in [9]. Moreover, the total probability of the negative impact of various risk factors can be identified as the main evaluation criterion. Thus, for each construction object or urban economy creating environmental risk, it is first necessary to determine the factors of the negative impact on the surrounding urban environment (polluting substances and physical fields), and then the sources of these factors.

In this case, the risk of the population of the territory adjacent to the territory of the location of the urban infrastructure or urban facilities that have a negative impact on the surrounding urban environment can be expressed by the formula:

$$
R=\sum_{j=1}^{n} P_{j-\text { year }}=\sum_{j-1}^{n}\left[1-\prod_{i=1}^{12}\left(1-P_{i j-\text { month }}\right)\right]
$$

where: Pj-year - probability of negative impact of j-factor during the year; Pij-month probability of negative impact of $\mathrm{j}$ - factor during i month.

In the works $[2,10]$, it was proposed to take into account the human factor as a relative indicator of environmental safety (IES) of the population living in the territory adjacent to the territory of the location of urban infrastructure or urban facilities, and subject to anthropogenic negative effects:

$$
I E S=1-e^{\left(-K_{s} / D_{\text {pop }}\right)}
$$

where: $\mathrm{D}_{\text {pop }}$ - relative indicator of economic damage to the population, determined by the formula (1), and $K_{s}$ - coefficient of public protection, characterizing the effectiveness of the application of methods, means and systems of environmental protection:

$$
K_{s}=\frac{E_{n a t}+E_{\text {art }}}{E_{\text {nat }}}
$$

The environmental risk of the population living in the territory adjacent to the territory of the placement of urban infrastructure, or urban facilities and subject to negative impacts, is the basis for drawing up territory comfort maps. In this case, event A, consisting in the occurrence of a disease, and some factor $\mathrm{F}$, negatively affecting the urban environment and affecting the occurrence of disease A, are taken into account. In this case, the definition of risks is based on Bayes' theorem, the mathematical interpretation of which is the following:

$$
P(A, F)=P\left(\frac{A}{F}\right) P(F)=P(F, A)=P\left(\frac{F}{A}\right) P(A)
$$

where: $\mathrm{P}(\mathrm{A}, \mathrm{F})=\mathrm{P}(\mathrm{F}, \mathrm{A})$ - mutual probability of observing the disease and factor; $\mathrm{P}(\mathrm{A} / \mathrm{F})$ conditional probability of a disease under the influence of a factor; $\mathrm{P}$ (F / A) - conditional probability of observing a factor among patients; $\mathrm{P}(\mathrm{F})$ - probability of factor exposure (probability to meet in this group a person who has been exposed to the factor); P (A) - the probability of illness among the population.

The indicator of risk change when exposed by factor $F$ is the relative risk $P(A / F)$, determined by the ratio of the mutual probability to either the probability of exposure to the 
factor or the probability of the disease. This value shows by how many times the risk of the disease changes when the factor acts in relation to the average

The sequence of forming an assessment of the environmental safety level of construction objects and urban facilities based on an analysis of existing basic scientific approaches is presented by in Fig. 1 .

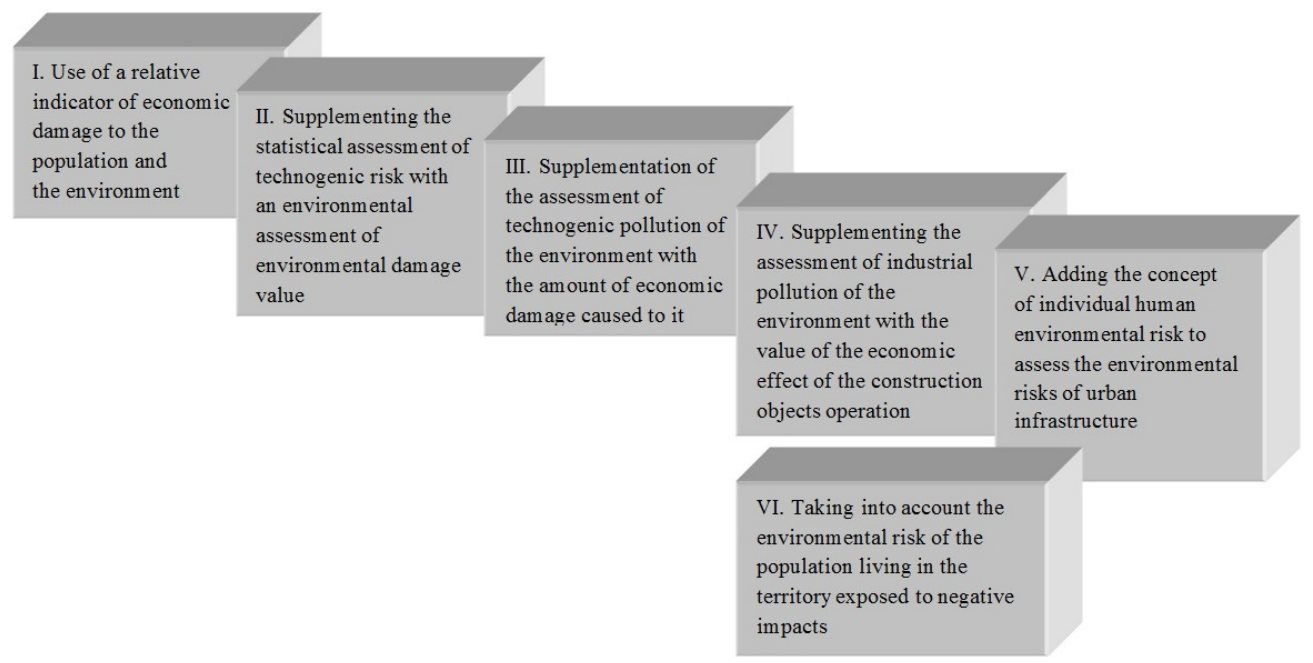

Fig. 1. The sequence of forming an assessment of the level of environmental safety of construction objects and urban economy based on the analysis of existing basic scientific approaches.

Thus, as a result of the research phase, we considered and analyzed the main scientific approaches currently used to assess the individual components of environmental safety in urban areas (see Fig. 1), and also identified their main advantages and disadvantages. In addition, an analysis of the above approaches made it possible to systematize the parameters and characteristics used in assessing the level of environmental safety in urban areas. It is these parameters and characteristics that are advisable to use in the formation of a methodology for a comprehensive assessment of the ecological safety of urban areas based on data on the pollution of individual components of the surrounding urban environment (atmosphere, water bodies, soil and vegetation cover) with pollutants and physical fields. However, such an integrated approach to assessing the environmental safety of urban areas, assuming the simultaneous solution of environmental, sanitary, hygienic, technical, organizational, social, economic and other problems, in our opinion, should also take into account data on the impact of environmental pollution of the urban environment and the improvement of the urban area under consideration on socio-demographic characteristics, as well as on the economic condition of the study area.

\section{Results}

For the formation of scientific and methodological principles for assessing the level of environmental safety of capital construction objects for various purposes based on an analysis of the environmental, social, health and economic characteristics of urbanized territories, we have formed the following groups of parameters:

- Group 1 - environmental parameters that characterize the state of the components of the urban environment at the considered points (see. Fig. 2); 


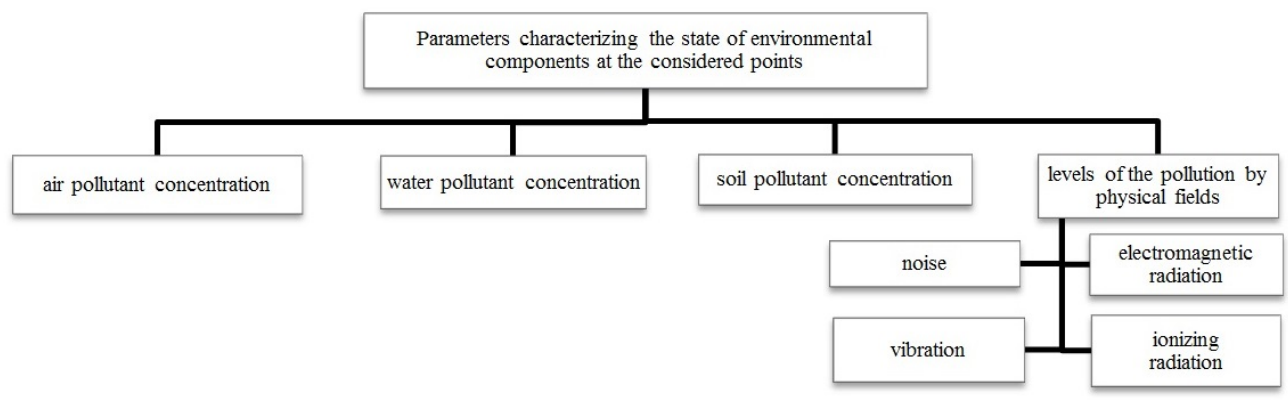

Fig. 2. The structure of the group of environmental parameters.

- 2nd group - economic and environmental parameters that characterize the economic activity that causes changes in the quality of the of the urban environment state (see Fig. 3);

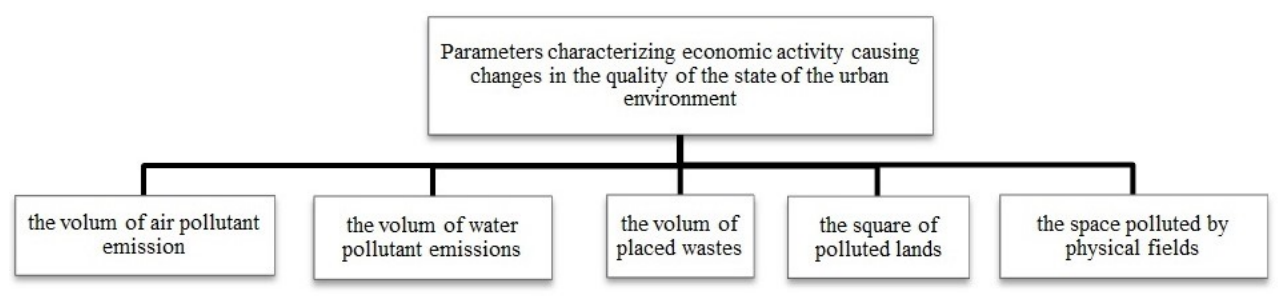

Fig. 3. The structure of the group of economic and environmental parameters.

- 3rd group - economic parameters that characterize the economic activity of the objects of the urbanized territory:

- economic damage to the urban environment. In theoretical terms, the economic damage from pollution of the urban environment has been studied quite fully $[4,11]$, as a result of which a methodology has been developed for assessing this damage, linking the natural indicators of emissions, discharges, waste, their degree of danger and territorial features with the economic indicators of urban and urban infrastructure households;

- economic expenses;

- economic benefits that characterize the benefits of the operation of construction objects and urban facilities located in the urbanized territory under consideration;

- parameters that characterize the costs of environmental measures of various directions.

The structure of the group of economic parameters is presented in Figure 4. 


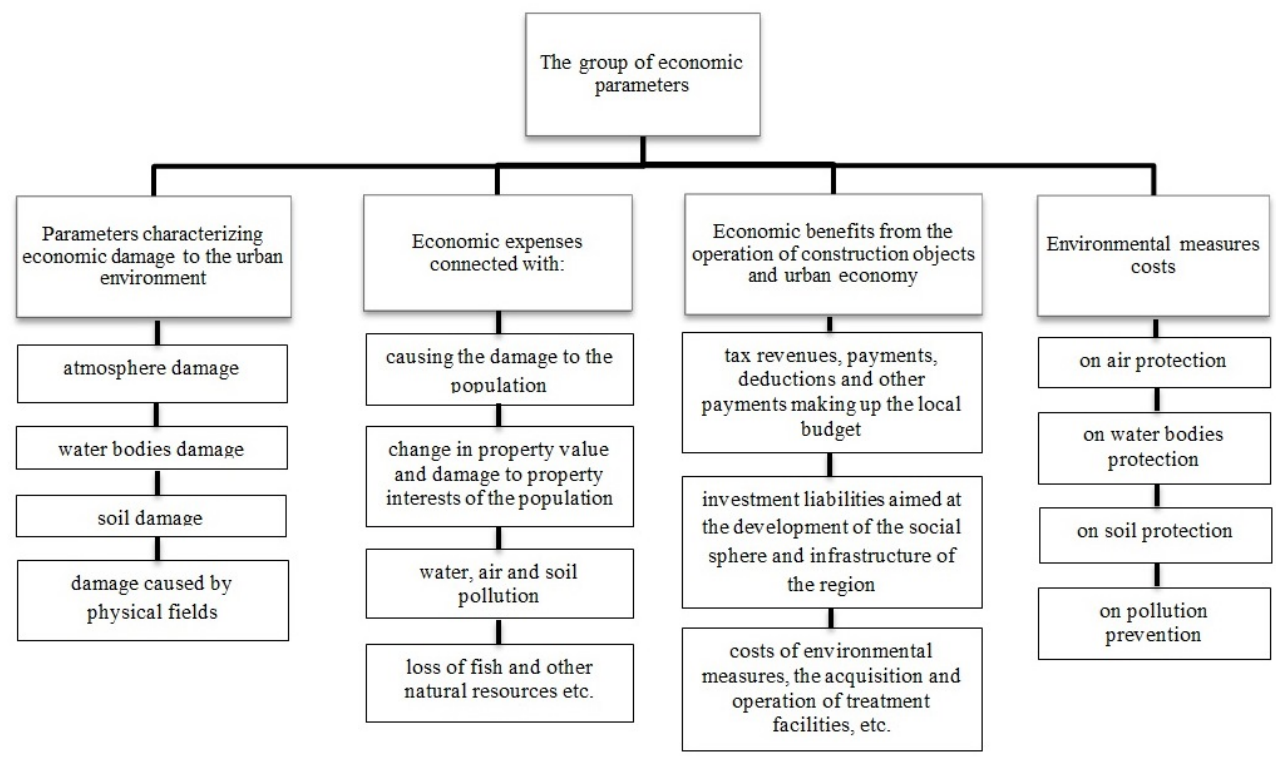

Fig. 4. The structure of the group of parameters, characterizing economic activity.

- 4th group - social parameters that reflect the level of health of the population living and working in the studied built-up area;

- parameters characterizing the living conditions of the population.

The structure of the group of social parameters is presented in Figure 5.

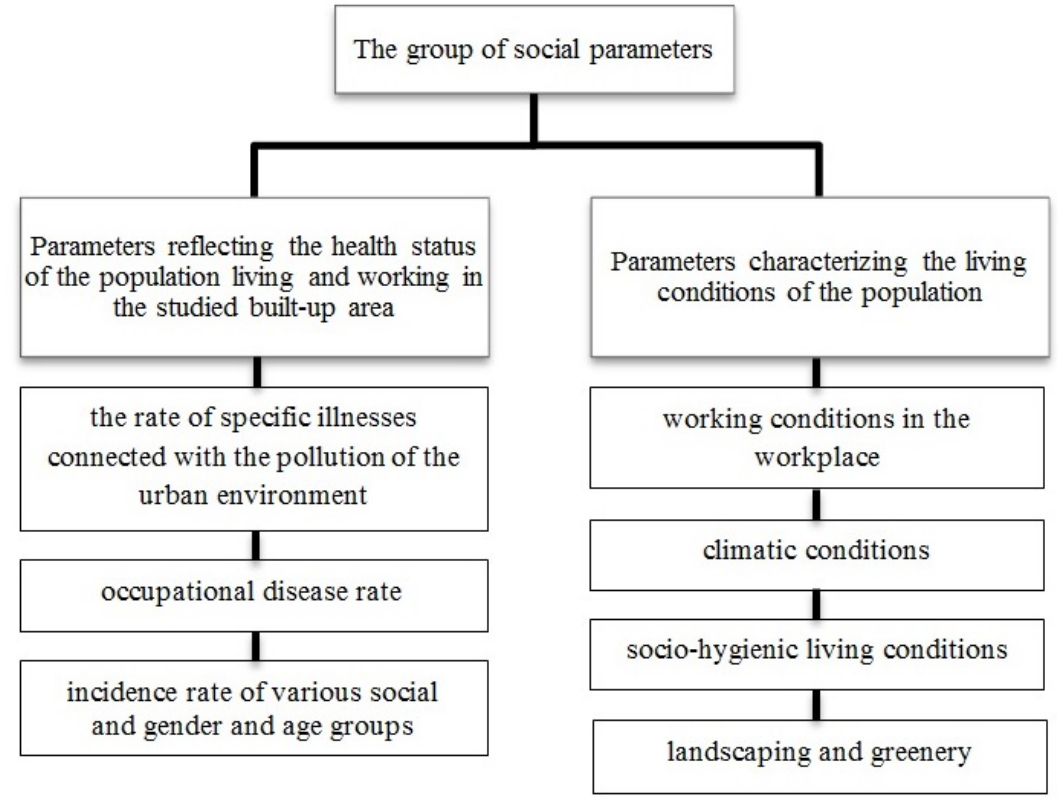

Fig. 5. The structure of the group of social parameters.

In accordance with the current environmental legislation in the Russian Federation, the degree of pollution of the urban environment is represented by the ratio of the actual values of the concentrations of pollutants and levels of pollution by physical fields to the environmental quality standards of the urban environment (TLV, PEL, etc.). According to 
the results of the study of the group of environmental parameters, it is necessary to consider the existing state and make a forecast of the quality of the state of the urban environment. Thus, the task of studying the first group of parameters is the formation of concentration fields of pollutants and levels of exposure to physical fields in the urban area under consideration.

The economic and environmental parameters listed in the second group make it possible to identify the main objects that have a negative impact on the urban environment and population in the urban area under study, as well as suggest ways to reduce this impact.

In modern conditions of ensuring sustainable development and ecological safety of cities, a transition is necessary from environmental protection, oriented mainly to restore the state of the urban environment after the damage has already been done, to rational environmental management as a system of sustainable long-term relations between the population and the urban environment, focused on preventive measures aimed at preventing possible damage. For this, we have defined a group of economic parameters that characterize the economic activity of the objects of the urbanized territory.

The parameters of the group of social parameters take into account the degree of influence of the level of pollution of the urban environment on the health status of the population, allow us to assess the health status of the population and its tendency to change. At the same time, the living conditions of the population make it possible to rank environmental and other factors by the degree of their impact on the health of the population, as well as establish causal relationships between the nature of the impact of the factor and the reaction of the human body.

Thus, the study of the theoretical foundations for assessing the level of environmental safety of urban environment objects allows us to conclude that the basic principles for the formation of such an assessment should be based on a comprehensive analysis and consideration of environmental, economic and social characteristics. As a result of analytical studies, we have identified the following scientific and methodological principles for the formation of an assessment of the level of environmental safety of urban environment objects:

- the principle of integrated consideration, based on the application of an integrated approach to the description of the state of the components of the urban environment;

- the principle of an interconnected consideration of the anthropogenic pollution value and the degree of change in the state of components of the urban environment;

- the principle of an interconnected consideration of the anthropogenic pollution value and the state of health of the population of the urban area under consideration;

- the principle of taking into account criteria describing the incidence of the population, living conditions, comfort and well-being of the urbanized territory under consideration;

- the principle of accounting for activities and their associated costs for ensuring the environmental safety of the considered urbanized territory;

- the principle of taking into account economic factors and characteristics of the urban area under consideration.

Table 1 provides a detailed list of the above principles and the main parameters on which they are based.

However, at present, the implementation of a comprehensive assessment that takes into account the above characteristics and is based on an analysis of the diverse functions of the urban area under consideration, the specifics and dynamics of its economic development, is a rather difficult task due to significant differences in the nature and dimension of the studied parameters and criteria. 
Table 1. Scientific and methodological principles of forming an assessment of the level of environmental safety of urban environment.

\begin{tabular}{|c|c|c|c|}
\hline $\begin{array}{c}\text { № index } \\
\text { number }\end{array}$ & $\begin{array}{c}\text { Scientific and } \\
\text { methodological principles }\end{array}$ & $\begin{array}{l}\text { The list of } \\
\text { parameters }\end{array}$ & Parameter Content \\
\hline \multirow[t]{4}{*}{1} & \multirow{4}{*}{$\begin{array}{l}\text { The principle of an } \\
\text { interconnected } \\
\text { consideration of the } \\
\text { anthropogenic pollution } \\
\text { value and the degree of } \\
\text { change in the state of } \\
\text { components of the urban } \\
\text { environment }\end{array}$} & \multirow{4}{*}{$\begin{array}{l}\text { parameters } \\
\text { characterizing the } \\
\text { state of the } \\
\text { components of the } \\
\text { urban environment } \\
\text { at the considered } \\
\text { points }\end{array}$} & air pollutant concentration \\
\hline & & & water pollutant concentration \\
\hline & & & soil pollutant concentration \\
\hline & & & $\begin{array}{l}\text { levels of pollution by physical } \\
\text { fields (noise, vibration, } \\
\text { electromagnetic and ionizing } \\
\text { effects) }\end{array}$ \\
\hline \multirow[t]{5}{*}{2} & \multirow{5}{*}{$\begin{array}{l}\text { The principle of an } \\
\text { interconnected } \\
\text { consideration of the } \\
\text { anthropogenic pollution } \\
\text { value and the degree of } \\
\text { change in the state of } \\
\text { components of the urban } \\
\text { environment }\end{array}$} & \multirow{5}{*}{$\begin{array}{l}\text { parameters } \\
\text { characterizing } \\
\text { economic activity } \\
\text { causing changes in } \\
\text { the quality of the } \\
\text { urban environment } \\
\text { state }\end{array}$} & $\begin{array}{l}\text { the volum of air pollutant } \\
\text { emission }\end{array}$ \\
\hline & & & $\begin{array}{l}\text { the volum of water pollutant } \\
\text { emissions }\end{array}$ \\
\hline & & & the volum of wastes placed \\
\hline & & & the square of polluted lands \\
\hline & & & $\begin{array}{l}\text { the space polluted by physical } \\
\text { fields }\end{array}$ \\
\hline \multirow[t]{2}{*}{3} & \multirow{2}{*}{$\begin{array}{l}\text { The principle of an } \\
\text { interconnected } \\
\text { consideration of the } \\
\text { anthropogenic pollution } \\
\text { value and the state of } \\
\text { health of the population }\end{array}$} & \multirow{2}{*}{$\begin{array}{l}\text { parameters } \\
\text { reflecting the health } \\
\text { status of the } \\
\text { population living } \\
\text { and working in the } \\
\text { studied built-up area }\end{array}$} & $\begin{array}{l}\text { incidence rate of various social } \\
\text { and gender and age groups }\end{array}$ \\
\hline & & & $\begin{array}{l}\text { death rate of various social and } \\
\text { gender and age groups }\end{array}$ \\
\hline \multirow[t]{6}{*}{4} & \multirow{6}{*}{$\begin{array}{l}\text { The principle of taking } \\
\text { into account criteria } \\
\text { describing the incidence } \\
\text { of the population, living } \\
\text { conditions, comfort and } \\
\text { well-being of the } \\
\text { urbanized territory under } \\
\text { consideration }\end{array}$} & \multirow{6}{*}{$\begin{array}{l}\text { parameters } \\
\text { characterizing the } \\
\text { living conditions of } \\
\text { the population }\end{array}$} & $\begin{array}{l}\text { living conditions of the } \\
\text { population }\end{array}$ \\
\hline & & & $\begin{array}{l}\text { working conditions in the } \\
\text { workplace }\end{array}$ \\
\hline & & & $\begin{array}{l}\text { climatic conditions (humidity, } \\
\text { pressure, level of insolation) }\end{array}$ \\
\hline & & & socio-hygienic living conditions \\
\hline & & & landscaping \\
\hline & & & greenery \\
\hline \multirow[t]{4}{*}{5} & \multirow{4}{*}{$\begin{array}{l}\text { The principle of } \\
\text { accounting for activities } \\
\text { and their associated costs } \\
\text { for ensuring the } \\
\text { environmental safety }\end{array}$} & \multirow{4}{*}{$\begin{array}{l}\text { parameters } \\
\text { characterizing the } \\
\text { costs of } \\
\text { environmental } \\
\text { measures }\end{array}$} & on air protection \\
\hline & & & on water bodies protection \\
\hline & & & on soil protection \\
\hline & & & $\begin{array}{l}\text { pollution by physical fields } \\
\text { prevention }\end{array}$ \\
\hline \multirow[t]{4}{*}{6} & \multirow{4}{*}{$\begin{array}{l}\text { The principle of taking } \\
\text { into account economic } \\
\text { factors and characteristics }\end{array}$} & \multirow{4}{*}{$\begin{array}{l}\text { parameters } \\
\text { characterizing } \\
\text { economic damage } \\
\text { to the urban } \\
\text { environment }\end{array}$} & atmosphere damage \\
\hline & & & water bodies damage \\
\hline & & & soil damage \\
\hline & & & damage caused by physical fields \\
\hline
\end{tabular}

\section{Discussion}

Achieving the goal of the research involves the development of a methodological approach, the basis of which is the improvement of existing methods for assessing the level of environmental safety of capital construction facilities for various purposes in urban areas. 
When forming this approach, we used the scientific and methodological principles mentioned above.

The practical implementation of well-known techniques devoted to the problem under study is often associated with significant difficulties in formalizing the depletion of natural resources, environmental damage and accounting the impact of urban environmental pollution on public health and a number of other problems. That is why there is a need to improve the methodological and statistical bases for assessing the level of environmental safety in urban areas.

When analyzing and justifying the need to change the technogenic type of development of urban areas to a sustainable type [12], we identified three types of restrictions: environmental, economic (investment) and social.

Environmental restrictions are associated with the need to prevent the degradation of the natural foundation for the development of urban areas. Every year, the risk of major technological accidents and environmental disasters increases, which is associated with a significant deterioration of buildings, structures, major urban facilities, as well as industrial, transport and sewage treatment equipment [13-14].

The second limitation of technological development is economic, or, in a narrower sense, investment. To maintain the technogenic, nature-intensive development, it is necessary to allocate more and more funds every year for the construction of new ones, reconstruction and renovation of existing municipal facilities. Obviously, with technogenic development, more and more funds are required even to maintain the efficiency of urban facilities at the same level, as well as to minimize the impact on the surrounding urban environment of urban infrastructure under construction, for example, shopping and entertainment centers and complexes (malls). Other, resource-saving ways of creating a sustainable urbanized area, including effective elements of urban infrastructure and urban facilities based on environmental factors, are needed.

Regarding social restrictions, we can conclude that the established technogenic type of development of urbanized territories is in the long run a dead end, not only due to environmental and economic restrictions, but also due to purely social reasons. Among them in the first place is the deterioration of public health [8-9]. The unsatisfactory state of the urban environment determines approximately $20-30 \%$ of the total incidence and $50 \%$ of cancer among the population of urban areas. Among other social problems caused by the deterioration of the urban environment, national and migration problems should be mentioned.

After analyzing the known methods, we concluded that the sustainable development of urban areas covers three main aspects - environmental, economic and social. That is why a comprehensive assessment, in our opinion, includes the definition of three criteria: first of all, environmental, but also economic and social. It should be taken into account that the most important methodological principle remains the formation of a complex of systemstructural relationships and the ranking of factors according to their importance.

The principles of forming an assessment of the level of environmental safety of urban environment objects mentioned above can be the basis for further development of the appropriate methodology, which, in our opinion, will allow:

- determine the consequences of the effectiveness of economic and other activities carried out in the territory under consideration, in terms of taking into account environmental, economic and social factors;

- optimize the measures proposed to increase the degree of environmental safety of construction objects and urban facilities of urbanized territories;

- develop options for pre-object, including pre-investment and object documentation, substantiating the planned activities of construction objects and urban facilities of urbanized territories; 
- carry out an environmental impact assessment of new construction objects and reconstructed urban facilities that appear in the updated infrastructure of modern cities.

\section{Conclusions}

Thus, the assessment of the environmental safety level of construction objects for various purposes in urban areas requires, first of all, the integrated consideration of environmental, economic and social criteria, each of which includes the corresponding groups of parameters (environmental, economic, social and economic).

Our scientific approach will allow, using the various characteristics of an urbanized area with different dimensions, to obtain the resulting criteria in a dimensionless form and thereby improve the methodology for calculating a comprehensive assessment of the level of environmental safety of construction objects and urban economy in urbanized areas.

\section{References}

1. V. Bespalov, E. Kotlyarova, Iop Conference Series: Earth and Environmental Science, 012036 (2018). doi: 10.1088/1755-1315/177/1/012036

2. V. Bespalov, E. Kotlyarova, E3S Web of Conferences, EDP Sciences, 01009 (2020). doi: 10.1051/e3sconf/202016401009

3. V. Ilyichev, S. Emelyanov, V. Kolchunov, N. Bakayeva, S. Kobeleva, Procedia Engineering, 117, 126-131 (2015). doi: 10.1016/j.proeng.2015.08.133

4. V. Bespalov, E. Kotlyarova, E3S Web of Conferences, EDP Sciences, 00060 (2019). doi: 10.1051/e3sconf/201912600060

5. V. Bespalov, E. Kotlyarova, Matec Web of Conferences, EDP Sciences, 05005 (2017). doi: 10.1051/matecconf/201712905005

6. S. Sheina, A. Fedorovskaya, Matec Web of Conferences, EDP Sciences, 07010 (2017). doi: 10.1051/matecconf/201710607010

7. V. M. Jayasooriya, A. W. M. Ng, S. Muthukumaran, S. Perera, Urban Forestry \& Urban Greening, 21, 34-47 (2017). doi: 10.1016/j.ufug.2016.11.007

8. R. A. Silva, K. Rogers, T. J. Buckley, Environmental Science \& Technology, 52, 95459555 (2018). https://doi.org/10.1021/acs.est.8b01781

9. S. J. Jordan, S. E. Hayes, D. Yoskowitz, L. M. Smith, J. K. Summers, M. Russel,

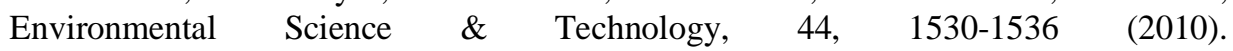
https://doi.org/10.1021/es902597u

10. S. Deshkar, V. Adane, Urban Disasters and Resilience in Asia, 245-267 (2016). doi: 10.1016/B978-0-12-802169-9.00016-1

11. K. Riahi, D. P. van Vuuren, E. Kriegler, J. Edmonds, B. C. O`Neill, S. Fujimori, etc. Global Environmental Change, 42, 153-168 (2017). https://doi.org/10.1016/j.gloenvcha.2016.05.009

12. R. G. G. Caiado, Dias R. Freitas, L. V. Mattenvironment, O. L. G. Quelhas and W. L. Filho, Journal of Cleaner Production, 165, 890-904 (2017). doi: 10.1016/j.jclepro.2017.07.166

13. V. Kumar, A. Sharma, A. Cerda, Heavy Metals in the Environment 1st Edition, Elsevier, 400 p. (2020).

14. S. Bhattacharyya, N. K. Mondal, J. Platos, V. Snasel, P. Kromer, Intelligent Environmental Data Monitoring for Pollution Management 1st Edition, Academic Press, 380 p. (2020). 